\title{
Research Paper: The Role of Alexithymia and Sexual Self-esteem in the Prediction of Marital Stress and Adjustment in Infertile Women
}

\author{
Arash Aghighi $^{1}$ (D), Marziye Foroughi², Saeede Daneshmandi ${ }^{*}$ (D), Moslem Abbasi ${ }^{3}$ (D) \\ 1. Department of Clinical Psychology, Faculty of Educational Science \& Psychology, Shiraz University, Shiraz, Iran. \\ 2. Department of Clinical Psychology, Faculty of Literature \& Humanistic Science, Bushehr Branch, Islamic Azad University, Bushehr, Iran \\ 3. Department of Psychology, Faculty of Literature \& Humanistic Science, Salman Farsi University of Kazerun, Kazerun, Iran.
}

\begin{tabular}{|c|c|}
\hline $\begin{array}{l}\text { Use your device toscan } \\
\text { and read the article online }\end{array}$ & \\
\hline aring & $\begin{array}{l}\text { in the Prediction of Marital Stress and Adjustment in Infertile Women. Journal of Practice in Clinical Psychology, 9(1), } 19-26 . \\
\text { https://doi.org/10.32598/jpcp.9.1.673.1 }\end{array}$ \\
\hline 마롤 & doli'https://doi.org/10.32598/jpcp.9.1.673.1 \\
\hline
\end{tabular}

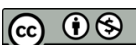

Article info:

Received: 16 May 2020

Accepted: 08 Aug 2020

Available Online: 01 Jan 2021

Keywords:

Alexithymia, Sexual selfesteem, Marital stress, Marital adjustment, Infertile women

\section{ABSTRACT}

Objective: Considering the negative impact of infertility on the level of adjustment and stress in women, the present study aimed to examine the role of sexual self-esteem and alexithymia in predicting marital stress and adjustment of infertile women.

Methods: This research was a cross-sectional study. The study population consisted of all infertile women in Shiraz City, Iran $(\mathrm{N}=70000)$. A total of 400 women were selected through a non-random and purposeful sampling method, but the final sample consisted of 380 subjects. The study tools were a short form of sexual self-esteem scale for women, Locke-Wallace marital adjustment questionnaire, Stockholm-Tehran marital stress scale, and Toronto alexithymia scale. The obtained data were analyzed by the Pearson correlation and multivariate regression in the SPSS V. 26.

Results: The results showed a significant negative relationship between sexual self-esteem and marital stress as well as alexithymia and marital adjustment $(\mathrm{P}<0.01)$. Besides, the positive relationships between sexual self-esteem and marital adjustment and alexithymia and marital stress were significant $(\mathrm{P}<0.01)$. The results of multiple regression analysis demonstrated that alexithymia and sexual self-esteem could significantly predict marital stress and marital adjustment with the standard coefficient of 0.44 and 0.22 , respectively.

Conclusion: Alexithymia and sexual self-esteem play essential roles in predicting adjustment and stress levels of infertile women, respectively. Accordingly, difficulty in emotional awareness at first, and then the low level of self-esteem in sexual function can decrease adjustment and increase stress in marital relationships. 


\section{Highlights}

- Alexithymia may have negative impact on adjustment of infertile women.

- Alexithymia can increase stress in infertile women.

- Low level of sexual self-esteem can affect on adjustment of infertile women.

- Low level of sexual self-esteem can increase stress in infertile women.

\section{Plain Language Summary}

Considering that infertility is a condition influencing the quality of life and its increasing prevalence among Iranian women, improving psychological well-being is very important in psychological services. This study was conducted to examine some psychological factors impacting marital stress and marital adjustment in infertile women. The results of this study showed that difficulty in identifying and expressing emotions and negative perception about the body image affect on infertile women's adjustment and stress in their marital relationship. Thus, improving emotion regulation skills and modifying infertile women's beliefs about their physical status can lead to more adjustment and less experienced stress in their marital relationships and enhance the quality of lives.

\section{Introduction}

$\Gamma$

nfertility is defined as the failure to become pregnant after 12 months of unprotected sexual intercourse (Vander Borght \& Wyns, 2018). Infertility leads to mental health problems in infertile couples (Rashid Khan, Iqbal, \& Afzal, 2019). These problems affect the treatment outcome of infertility, such as delaying or preventing ovulation (Rooney \& Domar, 2016). It is highly approved that infertility is stressful in couples' lives (Holley et al., 2015). It causes problems in marital adjustment (Kim, Shin, \& Yun, 2018) as it creates shame and loss of control and adverse effects on the sexual relationship (Pasch \& Sullivan, 2017).

Emotion regulation, which is associated with marital satisfaction (Rajabi, Hayatbakhsh, \& Taghipour M, 2015; Omidi \& Talighi, 2017), can manage and modify one's internal state and or outward behavior in different situations (Compas et al., 2014). Alexithymia is an emotion dysregulation disorder involving difficulty identifying and expressing emotions (Taylor \& Michael Bagby, 2014). It has destructive effects on infertile females (Basirat et al., 2019). It is demonstrated that alexithymia is associated with maladaptive coping strategies and psychological stress between infertile women (Gourounti, Anagnostopoulos, Griva, \& Vaslamatzis, 2016) and has a negative impact on the quality of their lives (Renzi, Trani, Solano, Minutolo, \& Tambelli, 2020). Barghi
Irani, Pirgholi, and Pirbayati (2017) showed that difficulty in describing emotions is one of the predictors of negative sexual functions and lower self-esteem in infertile women. Besides, Falahati and Mohammadi (2020) have found that alexithymia leads to marital dissatisfaction through disrupting emotional relationships between partners.

On the other hand, sexual dysfunction and sexual dissatisfaction are highly prevalent in infertile women (Aggarwal, Mishra, \& Jasani, 2013; Shahraki, Tanha, \& Ghajarzadeh, 2018). Sexual self-esteem, which is the predictor of marital satisfaction (Tavakolizadeh \& Rastgoo Nejad, 2016), is defined as a positive appraisal of one's own sexuality, including appraisals of sexual thoughts, feelings, and behaviors, as well as perceptions of one's own body in a sexual context (Hensel, Fortenberry, O'Sullivan, \& Orr, 2011). It is approved that women with infertility show lower self-esteem, sexual satisfaction, sexual relationship, and sexual self-esteem (Zayed \& El-Hadidy, 2020). Hwang (2017) depicted that infertility can lead to depression through a negative influence on the selfesteem and body image of infertile women.

In sum, infertility and inability to conceive can negatively affect different aspects of infertile couples' lives, such as marital relationships, sexual relationships, psychological well-being, and quality of life (Luk \& Loke, 2015). Considering that the prevalence of infertility in Iran is increasing (Akhondi et al., 2013) and infertile 
women face a higher risk of psychological distress (Kazmi, Jadoon, \& Rehman, 2016), improving their marital adjustment and helping them to manage their stress should be in the first line of psychological services. This study aimed to examine the roles of sexual self-esteem and alexithymia in predicting marital adjustment and marital stress in infertile women. To the best of our knowledge, this is one of the first studies investigating the relationships between these variables as an integrated model. In other words, this study tries to answer the question that whether sexual self-esteem and alexithymia play any role in predicting marital stress and marital adjustment of infertile women.

\section{Methods}

This research was a cross-sectional study. Therefore, in this study, sexual self-esteem and emotional skillfulness were predictor variables, and marital stress and marital adjustment were considered criterion variables. The participants were selected through a non-random and purposeful sampling method from all infertile women referring to gynecologists of Imam Raza Clinic in Shiraz City, $\operatorname{Iran}(\mathrm{N}=70000$ ). The inclusion criteria were being 20 to 40 years old, being able to read and write, and been married more than two years. The exclusion criteria were diagnosis of personality disorders and lifetime diagnosis of severe mental disorders of Axis I of DSM-5 (The Diagnostic and Statistical Manual of Mental Disorders-5) based on SCID5 (Structured Clinical Interview for DSM Disorders).

To guarantee the adequacy of the sample size for the generalizability of the results, the sample size was calculated by the Cochran formula at the error level of 0.05 . So, 380 infertile women were selected, and 20 more subjects were added because of the probable decrease of the questionnaires returned by the subjects. Finally, 400 subjects participated in the study. After obtaining informed consent from the subjects, self-report questionnaires were administered to all of them. To reduce the bias, the priority of the questionnaires for each subject was selected randomly.

\section{Study instruments}

Sexual Self-Esteem Index for Women-Short-Form (SSEI-W-SF)

The Sexual Self-Esteem Index for Women-Short-Form (SSEI-W-SF) has 35 items developed by Zeanah and Schwarz (1996) and measures effective responses in women's sexual evaluation. The items are scored on a 6-point Likert scale from 1 to 6 (completely disagree to completely agree). This questionnaire reflects the areas of sexual self-esteem, including experience and skill, attractiveness, control, moral judgment, and adaptation. A higher score indicates higher sexual self-esteem. The Cronbach alpha coefficient for the total score and subscales range from 0.80 to 0.92 (Zeanah \& Schwarz, 1996).

After psychometric evaluation of this scale by Farokhi and Shareh (2014), questions 1, 3, and 33, which had low correlations with the total scale, were removed, and 32 items were selected for the Persian version of the questionnaire. The Cronbach alpha coefficients are as follows: 0.92 for the whole scale, 0.86 for experience and skill, 0.88 for attraction, 0.80 for control, and 0.87 for adaptation (Farokhi \& Shareh, 2014).

\section{Locke-Wallace Marital Adjustment Test}

Locke-Wallace marital adjustment test is a 15 -item questionnaire. It was developed by Locke and Wallace (1959) and evaluates the degree of success of the spouses in the activities related to the marital adjustment. The total score is equal to the sum of the scores of all questions and ranges from 2 to 158 . Accordingly, scores of 100 and higher show marital satisfaction, and scores of less than 100 indicate conflicts in marital relationships. The internal consistency obtained through the SpearmanBrown formula was very good, and the correlation coefficient between the two halves of the questionnaire was 0.90 . Also, it has high validity for distinguishing between compatible and incompatible couples (Locke \& Wallace, 1959). The scores of this test are highly correlated with the Lock-Wallace prediction test. This result reflects the high congruent validity. The questionnaire is a scale to predict marital adjustment in the future (Locke \& Wallace, 1959). This test was translated and edited by Mazaheri to Farsi. In another study, the questionnaire's reliability using the Cronbach alpha and splitting was 0.71 and 0.92 , respectively (Sanayi, 2017). In this study, Amanollahi marital satisfaction index questionnaire was used to determine the validity of the Locke-Wallace marital adjustment questionnaire. The validity coefficient between these two questionnaires was 0.66 (Sanayi, 2017).

\section{Stockholm-Tehran Marital Stress Scale (STMSS)}

Stockholm-Tehran Marital Stress Scale (STMSS) is a structured interview for measuring marital stress. It was developed by Orth-Gomer et al. (2000) for researching women with heart disease. It can be used for research about men and other health problems, as well. The original scale has 17 questions which are scored 0 and 1 . The minimum and maximum scores are 0 and 27, respectively (Besharat, Shamsipour, \& Barati, 2006). A higher score 
means more stress experienced in the marital relationship. Orth Gomer et al. (2000) reported the Cronbach alpha of this scale around 0.77 . This scale has been normalized in Iran by Besharat et al. (2006). The internal consistency of the translated form of the scale calculated by the Cronbach alpha coefficient is 0.91 (Besharat et al., 2006). A 16-item version of the scale was developed after translating, editing, and making necessary revisions on the original scale. This scale is scored on a 5-point Likert-type scale ranging from 1 to 5 (very low to very high). Each subject's score ranges from 24 to 120 (two questions on the scale have 5 parts, and the total number of questions is 24).

\section{Toronto Alexithymia Scale (TAS-20)}

Toronto Aexithymia Scale (TAS-20) is a 20 -item questionnaire and is scored on a 5-point Likert-type scale ranging from 1 (completely disagree) to 5 (completely agree). It was developed by Bagby, Taylor and Parker (1994) and had three subscales of difficulty in identifying emotions, difficulty in describing emotions, and objective thinking. The total score is also calculated through the sum of the scores of three subscales. The psychometric properties of the Toronto alexithymia scale (20-item) have been examined in numerous studies (Bagby et al.,1994). In the Farsi version of this scale, The Cronbach alpha coefficients for the scores of three subscales were as follows: difficulty in identifying emotions, 0.85; difficulty in describing emotions, 0.75; and objective thinking, 0.72 . These values confirm a good internal consistency of the TAS. The test-retest reliability of the scale and its subscales were from 0.80 to 0.87 in two stages with a 4-week interval. The results of correlation coefficients between the TAS and emotional intelligence scale (-0.85), psychological well-being (-78.7), and psychological hopelessness $(0.44)(\mathrm{P}<0.001)$ indicate the congruent validity of this scale (Besharat, 2007).
To analyze the findings of this study, descriptive statistics were used to compare means and standard deviations. The Pearson correlation test and multiple regression were applied to analyze the hypotheses. It should be noted that examining presumptions, including normality and multicollinearity, were done before the inferential analysis. SPSS V. 26 was used for all statistical analyses of the obtained data.

\section{Results}

Table 1 presents the mean and standard deviation of the research variables. In order to test normality, the Kolmogorov-Smirnov normality test was used. Considering the calculated significance, the scores of all variables were distributed in the normal range $(\mathrm{P}>0.05)$. Therefore, the normality distribution assumption for using parametric tests was observed.

Results of the tolerance index test to examine the collinearity statistic between predictor variables showed that the value of tolerance index for predictor variables was close to $1(0.988=$ sexual self-esteem, $0.988=$ alexithymia). Therefore, a relatively linear situation had been established, and regression analysis could be used. Another presumption of regression is the Durbin-Watson test which controls the independence of error from each other. Since the Durbin-Watson statistic of the present regression model was 1.701 (between 1.5 to 2.5 ), it can be concluded that the errors are independent of each other, and the regression model can be used to test hypotheses. The hypothesis was whether alexithymia plays any role in predicting marital stress and marital adjustment of infertile women (hypothesis 1) and whether sexual selfesteem plays any role in predicting marital stress and marital adjustment of infertile women (hypothesis 2).

Table 1. The mean and standard deviation scores of marital stress, marital adjustment, sexual self-esteem, and alexithymia

\begin{tabular}{|c|c|c|}
\hline & Variables & Mean $\pm S D$ \\
\hline & Marital stress & $64.62 \pm 11.16$ \\
\hline & Marital adjustment & $100.23 \pm 19.36$ \\
\hline & Sexual self-esteem & $95.75 \pm 15.34$ \\
\hline \multirow{4}{*}{ Alexithymia } & Difficulty in identifying emotions & $13.63 \pm 2.53$ \\
\hline & Objective thinking & $18.65 \pm 2.52$ \\
\hline & Difficulty in expressing emotions & $13.77 \pm 3.93$ \\
\hline & Total & $46.04 \pm 5.84$ \\
\hline
\end{tabular}


Table 2. The Pearson correlation between sexual self-esteem and alexithymia and between marital stress and marital adjustment

\begin{tabular}{cccccc}
\hline & \multicolumn{1}{c}{ Variables } & Marital Stress & & \multicolumn{2}{c}{ Marital Adjustment } \\
\cline { 2 - 5 } & Correlation Coefficient & P & Correlation Coefficient & P \\
\hline Sexual self-esteem & $-0.279^{* *}$ & 0.000 & $-0.248^{* *}$ & 0.000 \\
Difficulty in identifying \\
emotions \\
Alexithymia & $0.429^{* *}$ & 0.000 & $0.121^{* *}$ & 0.019 \\
& $\begin{array}{c}\text { Objective thinking } \\
\text { Difficulty in expressing } \\
\text { emotions } \\
\text { Total }\end{array}$ & $0.251^{* *}$ & 0.000 & $0.102^{* *}$ & 0.048 \\
& $0.262^{* *}$ & 0.000 & $0.133^{* *}$ & 0.009 \\
\hline
\end{tabular}

$\mathrm{P} \leq 0.01$.

Table 3. Results of multiple regression to explain marital stress and marital adjustment

\begin{tabular}{ccccccccc}
\hline Model & SS & df & MS & F & P & R & $\mathbf{R}^{2}$ & ${\text { Adj } \mathbf{R}^{2}}^{2}$ \\
\hline Regression & 12871.18 & 2 & 6435.59 & 70.54 & 0.000 & 0.522 & 0.272 & 0.268 \\
Residual & 34394.25 & 377 & 91.23 & & & & & \\
Total & 47265.43 & 379 & & & & & & \\
\hline
\end{tabular}

The results of Table 2 indicate a negative relationship between sexual self-esteem and marital stress $(\mathrm{P}<0.001)$. Besides, the positive relationship between alexithymia and marital stress was significant $(\mathrm{P}<0.001)$. On the other hand, there was a negative relationship between alexithymia and marital adjustment and a positive relationship between sexual self-esteem and marital adjustment $(\mathrm{P}<0.001)$.

To examine the hypotheses, a regression model test was used. The result of this analysis is presented in Table 3. Also, the results of standard coefficients for each predicting variable are presented in Table 4.

The amount of $\mathrm{R}^{2}$ in Table 3 indicates that the model can explain $27 \%$ of variances in marital stress and marital adjustment. Additionally, the results of Table 4 dem- onstrated that alexithymia could significantly predict marital stress and marital adjustment with a standard coefficient of 0.44 (hypothesis 1). Also, sexual self-esteem can significantly predict marital stress and marital adjustment with a standard coefficient of 0.22 (hypothesis 2).

\section{Discussion}

The present study aimed to investigate the role of sexual self-esteem and alexithymia in predicting marital stress and marital adjustment in infertile women. According to the study results, alexithymia and sexual self-esteem play important roles in predicting adjustment and stress levels of infertile women, respectively. In other words, difficulty in emotional awareness at first and then a low level of self-esteem in sexual function can

Table 4. Standard coefficients of predicting variables

\begin{tabular}{|c|c|c|c|c|c|}
\hline \multirow{2}{*}{ Model } & \multicolumn{2}{|c|}{ Non-Standard Coefficients } & \multirow{2}{*}{$\begin{array}{c}\text { Standard Coefficient } \\
\text { Beta }\end{array}$} & \multirow{2}{*}{$\mathbf{t}$} & \multirow{2}{*}{$\mathbf{P}$} \\
\hline & B & Std E & & & \\
\hline Fixed number & 41.22 & 5.24 & - & 7.86 & 0.000 \\
\hline Sexual self-esteem & -0.165 & 0.032 & -0.227 & -5.12 & 0.000 \\
\hline Alexithymia & 0.851 & 0.084 & 0.446 & 10.08 & 0.000 \\
\hline
\end{tabular}


decrease adjustment and increase stress in marital relationships. This finding is consistent with some previous research (Gourounti et al., 2016; Renzi et al., 2020; Falahati \& Mohammadi, 2020; Rajabi et al., 2015; Omidi \& Talighi, 2017; Tavakolizadeh \& Rastgoo Nejad, 2016; Zayed \& El-Hadidy, 2020; Hwang, 2017).

The initial finding of this study support that alexithymia and difficulty in emotional awareness have negative influences on the adjustment and stress level of infertile women in their marital relationship. This result is consistent with previous studies approving the relationship between alexithymia and marital psychological problems (Gourounti et al., 2016; Renzi et al., 2020; Falahati and Mohammadi, 2020; Rajabi et al., 2015; Omidi \& Talighi, 2017). There is no doubt that infertility and its treatment process are so stressful, and infertile women suffer from shame, guilt, anger, sadness, and loss of control. Besides, uncertainty about the treatment outcome can contribute to feeling these emotions at the highest level. Women with difficulty in describing and expressing these emotions suffer more than others because not only are they unable to name these negative emotions, but they also have trouble sharing them with their partners. So, This condition leads to marital dissatisfaction, adjustment problem and increases psychological distress through disrupting emotional relationships between partners (Falahati \& Mohammadi, 2020) and establishing low coping strategies to regulate negative emotions (Gourounti et al., 2016).

Another finding of this study has shown that low selfesteem in a sexual relationship and negative perception of infertile women about their body images can cause problems in their marital adaptation and increase their marital stress. This finding is consistent with previous studies demonstrating the negative effect of low sexual self-esteem on the different aspects of the marital relationship (Tavakolizadeh \& Rastgoo Nejad, 2016; Zayed \& El-Hadidy, 2020; Hwang, 2017). Dealing with reproductive difficulties, including its diagnosis and treatment process, increases sexual dissatisfaction and marital psychological problems because the infertile women significantly focus on the outcome of the sexual relationship and the result of the intercourse (Aggarwal et al., 2013). Additionally, having a negative body image put infertile women at the high risk of depression (Hwang, 2017) and results in adjustment problem and marital distress.

There were some limitations in this study. First, the accuracy of self-report measures was under question because the subjects were afraid to provide real information. They may pretend to be good in order to appear mentally healthier than they really are. Second, the nonrandom sampling method has limited the generalizability of the findings.

\section{Conclusion}

It can be concluded that difficulties in identifying and expressing emotions as well as low self-esteem in the sexual relationship resulted from infertility, lead to psychological problems in the marital relationships of infertile women. Thus, these problems reduce the couple's adjustment and increase their stress. So, improving emotion regulation skills and modifying infertile women's beliefs about their body images can lead to more adjustment and less experienced stress in their marital relationships and, finally, enhance their quality of lives. It is suggested that the interested researchers in this area examine the impact of different therapeutic approaches focused on emotion regulation skills and cognitive restructuring on the marital satisfaction of infertile couples. The investigation of the roles of other aspects of emotion regulation skills and sexual function in predicting infertile women's marital satisfaction can provide a comprehensive picture of the influential factors in this regard.

\section{Ethical Considerations}

\section{Compliance with ethical guidelines}

There were no ethical considerations to be considered in this research.

\section{Funding}

This research did not receive any grant from funding agencies in the public, commercial, or non-profit sectors.

\section{Authors' contributions}

Conceptualization and supervision: Moslem Abbasi; Methodology and data analysis: Arash Aghighi; Investigation, writing - original draft, and writing - review \& editing: Saeede Daneshmandi; Data collection: Marziye Foroughi; Funding acquisition and Resources: All authors.

\section{Conflict of interest}

The authors declared no conflict of interest.

\section{References}

Aggarwal, R. S., Mishra, V. V., \& Jasani, A. F. (2013). Incidence and prevalence of sexual dysfunction in infertile females. Mid- 
dle East Fertility Society Journal, 18(3), 187-90. [DOI:10.1016/j. mefs.2013.02.003]

Akhondi, M. M., Kamali, K., Ranjbar, F., Shirzad, M., Shafeghati, S., \& Ardakani, Z. B., et al. (2013). [Prevalence of primary infertility in Iran in 2010 (Persian)]. Iranian Journal of Public Health, 42(12), 1398-404. [PMID] [PMCID]

Bagby, R. M., Taylor, G. J., \& Parker, J. D. (1994). The twenty-item Toronto Alexithymia Scale-II. Convergent, discriminant, and concurrent validity. Journal of Psychosomatic Research, 38(1), 33-40. [DOI:10.1016/0022-3999(94)90006-X]

Barghi Irani, Z., Pirgholi, F., \& Pirbayati, Z. (2017). [The role of the self-esteem, perceived stress, alexithymia and cognitive avoidance on the sexual function of the fertilized and unfertilized women (Persian)]. Nursing and Midwifery Journal, 15(2), 95-106. https://unmf.umsu.ac.ir/article-1-3043-en

Basirat,Z., Faramarzi, M., Esmaelzadeh,S., Abedi Firoozjai,S.H.,Mahouti, T., \& Geraili, Z. (2019). Stress, depression, sexual function, and alexithymia in infertile females with and without polycystic ovary syndrome: A case-control study. International Journal of Fertility \& Sterility, 13(3), 203-8. [DOI:10.1177/0898010116675987] [PMID] [PMCID]

Besharat, M. A. (2007). Reliability and factorial validity of a Farsi version of the 20-item Toronto Alexithymia Scale with a sample of Iranian students. Psychological Reports, 101(1), 209-20. [DOI:10.2466/PR0.101.5.209-220] [PMID]

Besharat, M. A., Shamsipour, H., \& Barati, N. (2006). [Reliability and validity of Stockholm-Tehran Marital Stress Scale (STMSS) (Persian)]. Psychoscience, 5(19), 217-25. https://www.sid.ir/fa/ journal/ViewPaper.aspx?ID=143703

Compas, B. E., Jaser, S. S., Dunbar, J. P., Watson, K. H., Bettis, A H., \& Gruhn, M. A., et al. (2014). Coping and emotion regulation from childhood to early adulthood: Points of convergence and divergence. Australian Journal of Psychology, 66(2), 71-81. [DOI:10.1111/ajpy.12043] [PMID] [PMCID]

Falahati, F., \& Mohammadi, M. (2020). Prediction of marital burnout based on automatic negative thoughts and alexithymia among couples. Journal of Midwifery and Reproductive Health, 8(2), 2218-26. [DOI:10.22038/JMRH.2020.43917.1522]

Farokhi, S., \& Shareh, H. (2014). [Psychometric properties of the persian version of the sexual self-esteem index for woman-short form (Persian)]. Iranian Journal of Psychiatry \& Clinical Psychology, 20(3), 252-63. http://ijpcp.iums.ac.ir/article-1-2240-en.html

Gourounti, K., Anagnostopoulos, F., Griva, F., \& Vaslamatzis, G (2016). Alexithymia and fertility-related stress. Women \& Health, 56(3), 312-25. [DOI:10.1080/03630242.2015.1088119] [PMID]

Hensel, D., Fortenberry, J., O'Sullivan, L., \& Orr, D. (2011). The developmental association of sexual self-concept with sexual behavior among adolescent women. Journal of adolescence, 34(4), 675-84. [DOI:10.1016/j.adolescence.2010.09.005] [PMID] [PMCID]

Holley, S. R., Pasch, L. A., Bleil, M. E., Gregorich, S., Katz, P. K., \& Adler, N. E. (2015). Prevalence and predictors of major depressive disorder for fertility treatment patients and their partners. Fertility and Sterility, 103(5), 1332-9. [DOI:10.1016/j.fertnstert.2015.02.018] [PMID] [PMCID]

Hwang, R. H. (2017). Self-esteem, body image and factors influencing on depression of infertile women. Journal of Digital Convergence, 15(10), 537-49. [DOI:10.14400/JDC.2017.15.10.537]
Kazmi, S. F., Jadoon, A., \& Rehman, A. (2016). Impact of infertility duration on mental health of infertile women. Journal of The Society of Obstetricians and Gynaecologists of Pakistan, 6(2), 83-8. https://www.researchgate.net/publication/306505879_Impact_of_Infertility_Duration_on_Mental_Health_of_Infertile_Women/link/57bebb0708aeb95224d09ff5/download

Kim, J. H., Shin, H. S., \& Yun, E. K. (2018). A dyadic approach to infertility stress, marital adjustment, and depression on quality of life in infertile couples. Journal of Holistic Nursing, 36(1), 14-6. [DOI:10.1177/0898010116675987] [PMID]

Locke, H. J., \& Wallace, K. M. (1959). Short marital-adjustment and prediction tests: Their reliability and validity. Marriage and Family Living, 21(3), 251-5. [DOI:10.2307/348022]

Luk, B. H. K., \& Loke, A. Y. (2015). The impact of infertility on the psychological well-being, marital relationships, sexual relationships, and quality of life of couples: A systematic review. Journal of Sex $\mathcal{E}$ Marital Therapy, 41(6), 610-25. [DOI:10.1 080/0092623X.2014.958789] [PMID]

Omidi, A., \& Talighi, E. (2017). [Prediction couple's marital satisfaction based on emotion regulation (Persian)]. International Journal of Educational \& Psychological Researches, 3(3), 157-62. [DOI:10.4103/2395-2296.204120]

Orth-Gomer, K., Wamala, S. P., Horsten, M., Schenck-Gustafsson, K., Schneiderman, N., \& Mittleman, M. A. (2000). Marital stress worsens prognosis in women with coronary heart disease: The Stockholm female coronary risk study. Jama, 284(23), 3008-14. [DOI:10.1001/jama.284.23.3008]

Pasch, L. A., \& Sullivan, K. T. (2017). Stress and coping in couples facing infertility. Current Opinion in Psychology, 13, 131-5. [DOI:10.1016/j.copsyc.2016.07.004] [PMID]

Rajabi, G., Hayatbakhsh L., \& Taghipour, M. (2015). [Structural model of the relationship between emotional skillfulness, intimacy, marital adjustment and satisfaction (Persian)]. Journal of Family Counseling and Psychotherapy, 5(1), 68-92. http:/ / fcp. uok.ac.ir/article_11241_0.html?lang=en

Rashid Khan, A., Iqbal, N., \& Afzal, A. (2019). Impact of Infertility on mental health of women. The International Journal of Indian Psychology, 7(1), 804-9. [DOI:10.25215/0701.089]

Renzi, A., Trani, M. D., Solano, L., Minutolo, E., \& Tambelli, R. (2020). Alexithymia, infertility-related stress and quality of life in women undergoing an Assisted Reproductive Treatment. Stress and Health, 36(5), 654-62 [DOI:10.1002/smi.2967] [PMID]

Rooney, K. L., \& Domar, A. D. (2016). The impact of stress on fertility treatment. Current Opinion in Obstetrics and Gynecology, 28(3), 198-201. [DOI:10.1097/GCO.00000000000000261] [PMID]

Sanayi, B. (2017). [Family and Marriage Scale (Persian)]. Tehran Besat.

Shahraki, Z., Tanha, F. D., \& Ghajarzadeh, M. (2018). Depression, sexual dysfunction and sexual quality of life in women with infertility. BMCWomen's Health, 18(1), 1-4. [DOI:10.1186/ s12905-018-0584-2] [PMID] [PMCID]

Tavakolizadeh, J., \& Rastgoo Nejad, F. (2016). Sexual self-esteem as a predictor of marital satisfaction in mothers with normal or mentally retarded children. International Journal of Life Science and Pharma Research, (1), 1-8. 
Taylor, G. J., \& Michael Bagby, R. (2014). Advance in theory and research on alexithymia. In G. J. Taylor, R. M. Bagby, V. Caretti \& A. Schimmenti (Eds.), The Assessment of the Alexithymia Construct With the TSIA (pp. 77-97). Milano: Raffaello Cortina Editore.

Vander Borght, M., \& Wyns, C. (2018). Fertility and infertility: Definition and epidemiology. Clinical Biochemistry, 62, 2-10. [DOI:10.1016/j.clinbiochem.2018.03.012] [PMID]

Zayed, A. A., \& El-Hadidy, M. A. (2020). Sexual satisfaction and self-esteem in women with primary infertility. Middle East Fertility Society Journal, 25(1), 1-5. [DOI:10.1186/s43043-02000024-5]

Zeanah, P. D., \& Schwarz, J. C. (1996). Reliability and validity of the sexual self-esteem inventory for women. Assessment, 3(1), 1-15. [DOI:10.1177/107319119600300101] 